\title{
The genetic architecture of extended life span in the seed beetle Acanthoscelides obtectus (Coleoptera: Bruchidae)
}

\author{
DARKa ŠEŠLIJA ${ }^{1}$ and NiKOLA TUCIĆ1,2* \\ ${ }^{1}$ Department of Evolutionary Biology, Institute for Biological Research "Siniša Stankovi c", Blvd Despota Stefana 142, \\ 11060 Belgrade, Serbia; e-mail: ntucic@ibiss.bg.ac.yu \\ ${ }^{2}$ Faculty of Biology, University of Belgrade, Studentski trg 16, 11000 Belgrade, Serbia
}

Key words. Bruchidae, Acanthoscelides obtectus, ageing, genetic architecture, epistasis, longevity

\begin{abstract}
We studied the genetic architecture of the differences in the longevity between lines selected for postponed senescence and a control population of the seed beetle Acanthoscelides obtectus maintained on two hosts. By using lines with increased longevity, which were obtained by selection on natural variation in longevity, we showed that the genetic architecture of seed beetle longevity is complex, with sex-specific effects and variation attributable to many interacting genes, whose expression depend on the host on which the beetles were reared. The nonadditive genetic effects were more strongly expressed when reared on chickpeas, a novel host, than on beans. Outbreeding depression, with respect to longevity, was a consequence of both the intrinsic effect of interactions between genes from different parental sources (disruption of coadapted gene complexes) and the genotype $\times$ host interaction (loss of local adaptation).
\end{abstract}

\section{INTRODUCTION}

The identification of the underlying mechanisms that limit life span and generate variation in life span between individuals, sexes, populations and species is regarded as an elusive task, largely due to the fact that ageing processes are controlled by many interacting genes, the expression of which is sensitive to the environment. Studies on model organisms (Drosophila, Caenorhabditis elegans and mice) have identified numerous genes that influence life span and rates of senescence (Harshman, 2002). Estimates of heritability of longevity are of the order of 10-30\% (Finch \& Tanzi, 1997), indicating that natural and laboratory populations can harbour substantial quantitative genetic variation for longevity.

Understanding why organisms senesce and die, as well as, why there is considerable genetic variation for longevity in natural populations, are long standing topics in evolutionary biology. Classical explanations, based on the fact that the strength of natural selection decreases with age (Medawar, 1952; Williams, 1957; Hamilton, 1966; Charlesworth, 1994), have generated two hypotheses that are not mutually exclusive. The hypothesis proposed by Williams (1957) points to the fact that genes can have a pleiotropic effect on fitness so that an increase in fitness in early life is accompanied by a decreased fitness later in life. Because younger age classes contribute more to fitness than older age classes, genes with such pleiotropy remain in populations because natural selection will act more strongly on the earlier effects. The second hypothesis (Medawar, 1952) explains ageing and genetic variation for longevity through the accumulation of lateacting deleterious mutations. Because older age classes contribute less to fitness, there is less selection against deleterious mutations (modified version of Medawar's hypothesis assumes a moderate age specificity of allelic effects; see Reynolds et al., 2007). So, deleterious mutations affecting older age classes are at higher frequencies than those affecting younger age classes. Laboratory evolution experiments indicate that genetic variation of the kind postulated by these hypotheses (i.e. age-specificity of genetic effects) can indeed be exploited by selection (Rose 1984; Zwaan et al., 1995; Tucić et al., 1997; Partridge et al., 1999; Stearns et al., 2000).

Recently, there has been an accumulation of data regarding the genetic pathways affecting longevity and/or rates of senescence (Finch \& Tanzi, 1997; GeigerThornsberry \& Mackay, 2004). For example, Curran \& Ruvkun (2007) have identified 64 genes or about 2.4\% out of the 2,700 genes essential for normal development tested, as major life span regulators in C. elegans. Given that about $90 \%$ of the genes identified in this study are conserved from yeast to humans, it is possible that a substantial fraction of the genome could affect longevity. However, despite this our knowledge of the genes causing the naturally occurring the variation in longevity is very limited. As pointed out by Wilson et al. (2006), it is not yet clear whether the natural variants of genes affecting longevity represent a subset of genes identified by analysis of a single gene mutant, or are organisms in a normal ageing situation affected by undiscovered novel genes and pathways. The recent discovery that the life span of a well known mutant in D. melanogaster named "Indy" (I'm not dead yet) does not increase when the genetic background effects are removed (Toivonen et al., 2007), provides an illustration that variation attributable

\footnotetext{
* Corresponding author.
} 
to many interacting loci can be the major determinant of longevity associated with single gene mutations. Furthermore, the high sensitivity of longevity to genetic background and environment is reported for other "ageing genes" (Spencer et al., 2003; Baldal et al., 2006), indicating that epistatic interactions are important for genes affecting longevity.

Accordingly, when dealing with a topic as complex as the underlying mechanism of ageing, it is essential to determine the genetic architecture (number of genes and nature of interactions between alleles within and between loci) of natural variation in longevity. This could be achieved either by studying the genetic architecture of differences in longevity between natural populations, or, of replicated lines obtained by selecting for natural variants of genes affecting ageing in the laboratory. For example, a study of the genetic architecture of the differences in longevity and shapes of the mortality curves of South Indian and Burkina Faso populations of the seed beetle Callosobruchus maculatus (Fox et al., 2004) indicates that the genetic architecture is complex, with dominance and epistasis having a significant effect on variation in life span. Dominance and epistasis is recorded in quantitative trait locus (QTL) studies on D. melanogaster (Leips \& Mackay, 2000, 2002). Moreover, by using the old (O) lines selected for postponed senescence via later reproduction and their unselected control or base (B) lines, Wilson et al. (2006) revealed that there is a minimum of 11 QTLs on the third chromosome of $D$. melanogaster that affect the difference in longevity of the $\mathrm{O}$ and $\mathrm{B}$ lines. Interestingly, none of the QTLs include candidate genes that have previously been associated with effects on longevity, indicating that analysis of natural variants with small effects could indeed uncover novel genes affecting longevity.

Given the complexity of the genetic architecture of longevity in Drosophila and several other model species, it is becoming clear that we still do not know how common or necessary nonadditive genetic effects on longevity are in the process of population divergence. Is the genetic architecture of natural variation in longevity in other species also complex, with variation attributable to many interacting genes sensitive to environmental conditions, or more simple, with relatively few genes with large additive effects contributing to most of the variation in longevity? Therefore, to understand the differences in longevity among species, the studies on genetic architecture of longevity must be conducted on many species in different environments.

As part of our effort to elucidate the mechanisms of the ageing process in the seed beetle (Acanthoscelides obtectus), we produced replicated lines selected for postponed senescence that live longer (Gliksman \& Tucić, 1991; Tucić et al., 1997). The lines used in this study were obtained from later generations of lines selected for latelife reproduction. Here, we report the quantitative genetic basis of the difference in longevity between these lines and their unselected control population. Also, we examine whether the genetic architecture of longevity depends on the host in which beetles develop. The important advantage of using lines with extended longevity is that they were obtained by selection of allelic variations affecting many loci within outbred populations of $A$. obtectus. We show that the genetic architecture of natural variation in longevity of $A$. obtectus is complex, with sex-specific effects and variation attributable to many interacting loci, the expression of which depends on the host in which the beetles developed. Our results suggest that further quantitative genetic studies on longevity will increase our understanding the genetic basis and evolution of complex phenotypic traits.

\section{MATERIAL AND METHODS}

\section{Life history and experimental conditions}

The seed beetle, Acanthoscelides obtectus (Coleoptera: Bruchidae), is a cosmopolitan pest of stored legumes. The main host of this bruchid species is the seed of the common bean (Phaseolus vulgaris). Larval survival, however, is satisfactory when reared on chickpeas (Cicer arietinum) or seed of other legumes. The females lay eggs in a cluster under or near a single seed. Approximately four to six days later (at $30^{\circ} \mathrm{C}$ ), the eggs hatch and the first instar larvae burrow into the seed. Larval development and pupation are completed entirely within a single seed. Adults are facultatively aphagous, i.e. they need neither food nor water in the adult stage. A. obtectus is well adapted to living in dry seeds, has recently colonized seeed stores, and is able to mate and complete reproduction using only metabolic water and resources acquired during larval development.

The experiments were conducted in the dark in an incubator at $30^{\circ} \mathrm{C}$ and a relative humidity of about $70 \%$. All seeds, bought in bulk from one source, were frozen before use in the experimental treatments. No food or water was offered to experiment adults.

\section{Experimental lines and design}

All the beetles used in this study were derived from a population that has been maintained in our laboratory since 1986. This population ("base") originated from a mass mating of equal numbers of adults from three local populations of A. obtectus, infesting seeds of the common bean, in the vicinity of Belgrade (Serbia), an area where the chickpea is not grown. This base population is large (about 5,000 individuals per generation) and maintained on Phaseolus vulgaris seeds, which is changed at intervals of about 40-days.

We examined the genetic architecture of the differences in adult longevity of an unselected control population $(\mathrm{C})$ and the old (O) lines selected for postponed senescence. The $\mathrm{C}$ population was established from a sample of about 1,000 unsexed individuals randomly chosen from the base population and cultured on chickpeas (Cicer arietinum), a novel host for these beetles. The host shift imposed on the $\mathrm{C}$ line resulted in new conditions for larval development and competition, because the size of the seeds, as well as the texture and hardness of the seed coat, are different. In addition, these seeds differ in composition and concentration of chemical defense substances; beans, for example, lack L-cavaninin, a toxic secondary compound, present in chickpeas (Bisby et al., 1994). The C population was maintained, at about 1,000 adults per generation, on chickpeas for 150 generations prior to the present experiment.

The old lines were obtained by selecting for 117 generations for postponed senescence via late-life reproduction. Beetles in the $\mathrm{O}$ selected lines were allowed to reproduce from the 10th 
day after emergence until death. Prior to that period, experimental adults were kept in vials (females and males together) without beans (in the absence of beans, egg production is low). Four replicates, reared on beans, were maintained for this selection regime. All the assays of the $\mathrm{O}$ lines described below were done using four-way crosses. These crosses were obtained by crossing the $\mathrm{F}_{1} \mathrm{~S}$ of different pairs of replicate lines, that is, $\left(\mathrm{O}_{1} \times\right.$ $\left.\mathrm{O}_{2}\right) \times\left(\mathrm{O}_{3} \times \mathrm{O}_{4}\right)$, where the subscript numbers refer to the specific replicate lines. The outcrossing of replicate lines should remove any effects of inbreeding depression and diminish any epistatic interaction among genes originating from long-term selection, due to genetic drift or mutation pressures. Also, protocols used to construct four-way crosses ensured that selected lines passed through two generations under the same conditions (see Tucić et al., 1997, for details).

The $\mathrm{C}$ and $\mathrm{O}$ (i.e. their four-way crosses) lines were crossed to produce $F_{1}$ and $F_{2}$ generations and two backcross generations, the $B_{1}$ and $B_{2}$ generations (i.e. $F_{1} \times P_{1}$ and $F_{1} \times P_{2}$ ). Reciprocals of all crosses were established, denoted as $\mathrm{rF}_{1}, \mathrm{rF}_{2}, \mathrm{rB}_{1}$, and $\mathrm{rB}_{2}$. For each backcross, separate generations were raised, in which the $\mathrm{F}_{1}$ parent differed reciprocally; e.g. $\left(\mathrm{P}_{1} \times \mathrm{P}_{2}\right) \times \mathrm{P}_{1}$ and $\left(\mathrm{P}_{2} \times\right.$ $\left.\left.\mathrm{P}_{1}\right) \times \mathrm{P}_{1}\right)$. Thus, we created 14 distinct crosses. All crosses were set up with a minimum of 100 virgin individuals of each sex as parents.

In order to test for host-specific effects on the genetic architecture of longevity we established two independent sets of crosses between the $\mathrm{C}$ and $\mathrm{O}$ lines. The first was set up in bottles containing beans; the second in bottles containing chickpeas. Thus, within each set of crosses all larvae were raised on either beans, the host of the $\mathrm{O}$ lines, or chickpeas, the host of the $\mathrm{C}$ lines.

Longevity (we use life span and longevity interchangeably; both refer to age at death) from adult emergence until death was estimated in test vials contaning between 10 to 20 virgin beetles - females or males. The virgin females or males emerging on a particular day were kept in separate vials (there were up to 15 subgroups per experimental treatment). The number of dead beetles was counted every day. In total, we recorded the life span for 5728 females (2738 reared on beans and 2990 reared on chickpeas) and 6588 males (3065 reared on beans and 3523 reared on chickpeas).

\section{Genetic analyses}

We tested for additivity, dominance, epistasis and maternal contribution to divergence of parental lines using joint scaling tests of phenotypic means, a weighted least squares multiple regression technique that scales for differences in line means (Lynch \& Walsh, 1998). We used the expected phenotype of $F_{2}$ offspring as the point of reference, i.e. its mean phenotype is presented as $m$, and all the composite effects of various types of gene action are defined as zero in the $F_{2}$ background. The model of gene effects describing the behaviour of $F_{2}$ hybrids (or other segregational generation hybrids) in relation to their parents and $F_{1}$ is frequently referred to as the line-cross methodology. This approach is an especially powerful tool for detecting the disruption of putative co-adaptive gene complexes through recombination, because it permits a direct estimate of the contribution of epistasis to differentiation of populations (Fenster et al., 1997).

Linear models of genetic architecture with up to nine composite genetic parameters were fitted to the 14 cross means. The composite genetic parameters were estimated by minimizing the sum of the weighted residual squares $\left(R S S_{w}\right)$. The weight is given as:

$$
\mathrm{RSS}_{\mathrm{W}}=\sum_{i=1}^{k} \frac{e_{i}^{2}}{S E_{i}^{2}}
$$

where $k$ is the number of crosses, $e_{i}^{2}$ is the difference between observed and predicted composite genetic effects and $S E_{i}^{2}$ the standard error of the estimated composite genetic effect. Under assumption of normality, $R S S_{w}$ is $\chi^{2}$ distributed with the degrees of freedom equal to the number of lines minus the number of parameters in the model (Lynch \& Walsh, 1998); if significant, the model does not explain the observed means of the crosses.

We used Akaike's information criterion (AIC) to select the most parsimonious model, which is the best compromise between the amount of variance explained and the number of parameters in the model. The model with the lowest $A I C$ score is the most parsimonious. Bieri \& Kawecki (2003) showed that $A I C=R S S_{w}+2 K+$ constant, where $K$ is the number of parameters in the model. The constant can be omitted because it plays no role in the ranking of the models.

The observed 14 generation means were used to estimate the following parameters (Edinburgh/Iowa notation): an overall mean $(m)$, additive $[a]$, dominance $[d]$, additive $\times$ additive epistasis [aa], additive $\times$ dominance epistasis $[a d]$, dominance $\times$ dominance epistasis $[d d]$, an additive genetic maternal effect $[a m]$, a dominance genetic maternal effect $[d m]$, a cytoplasmic effect $[c]$ and a $\mathrm{Y}$ chromosome effect $[Y]$. To reduce the number of candidate models (there are $2^{9}=512$ possible models, $m$ being included in all models) we first tested models that included a cytoplasmic and Y chromosome effects. Since none of the most parsimonious models included these effects, we reduced the 14 crosses to nine crosses by pooling the two $F_{2}$, $\mathrm{B}_{1}, \mathrm{rB}_{1}, \mathrm{~B}_{2}$, and $\mathrm{rB}_{2}$ crosses into single $\mathrm{F}_{2}, \mathrm{~B}_{1}, \mathrm{rB}_{1}, \mathrm{~B}_{2}$, and $\mathrm{rB}_{2}$.

In addition, following the suggestion of Bieri \& Kawecki (2003), by pooling the three epistasis parameters ([aa], [ad], and $[d d]$ ) into $\mathrm{E}$, and the two forms of maternal effects ([am] and $[d m])$ into $\mathrm{M}$, we reduced the number of candidate models to $2^{4}=16$. The number of models was increased to include three forms of epistasis or the two forms of maternal effects, only if the most parsimonious models included $\mathrm{E}$ or $\mathrm{M}$.

To assess whether the three epistatic parameters significantly improved the fit of the model to the data, Bieri \& Kawecki (2003) recommend omitting them (if they were included in the model) or adding them to the model (if they were not included) and recalculating the $R S S_{w}$ value. The likelihood-ratio epistasis test $(\Lambda)$ has a $\chi^{2}$ distribution with 3 degrees of freedom (three because there are three epistasis parameters).

To test the contribution of epistasis to hybrid breakdown (i.e. if epistasis adversely affects the longevity of $F_{2}$ hybrids), we used a Bieri \& Kawecki modification of the $C$ scaling test (Gilchrist \& Partridge, 1999; Mather \& Jinks, 1982) in the following form

$$
C^{\prime}=-2[a \times a]-[d \times d]
$$

A significant negative $C^{\prime}$, which indicates hybrid breakdown, can thus be caused by positive additive $\times$ additive epistasis [aa] and dominance $\times$ dominance epistasis $[d d]$.

To test the difference between the genetic parameters estimated for the two hosts ( $m$ was not included in this analysis) we used the Wald chi-square statistic:

$$
\chi^{2}=\left(b_{1}-b_{2}\right)^{2} /\left[\mathrm{SE}\left(b_{1}\right)^{2}+\mathrm{SE}\left(b_{2}\right)^{2}\right]
$$

where $b_{1}$ and $b_{2}$ are the genetic parameters for each host, and $\operatorname{SE}\left(b_{1}\right)$ and $\operatorname{SE}\left(b_{2}\right)$ their standard errors (Allison, 1995). The sum of the Wald chi-square, with degrees of freedom equal to the number of parameters in the model, was used to assess the differences between models. Models with the same parameters were compared because the parameter estimates are sensitive to the parameters included in the model. If the number of parameters differed between hosts then for the purpose of hypothesis 
TABLE 1. Analysis of variance in longevity (data were $\ln$ transformed) of the parental lines of Acanthoscelides obtectus. Degrees of freedom are in the parentheses.

\begin{tabular}{ccc}
\hline Source of variation & Mean squares & \multicolumn{1}{c}{$F$ value } \\
\hline Line (1) & 15.12 & $195.47^{* * *}$ \\
Host (1) & 7.32 & $94.63^{* * *}$ \\
Line $x$ host (1) & 2.07 & $26.72^{* * *}$ \\
Sex (1) & 85.82 & $1109.62^{* * *}$ \\
Line $\times$ sex (1) & 3.31 & $42.81^{* * *}$ \\
Host $\times$ sex (1) & 0.67 & $8.64^{* *}$ \\
Line $\times$ host $\times$ sex (1) & 0.01 & 0.15 \\
Error $(1846)$ & 0.08 & \\
$* * P<0.01, * * * P<0.001$. & &
\end{tabular}

testing both parameters were included in the models to be compared although only one was significantly different from zero.

\section{RESULTS}

\section{Longevity and mortality curves of the parental lines}

Mean longevity differed significantly between lines $\mathrm{C}$ and $\mathrm{O}(P<0.001$; Table 1$)$; $\mathrm{O}$ beetles lived about 3 days (or 21\%) longer than $\mathrm{C}$ beetles (averaged across each sexhost combination). Also, there was a significant Line $\times$ host interaction $(P<0.001)$, indicating that environmental variation, rather than genetic background, could have mediated changes in genotypic values for longevity in the $\mathrm{C}$ and $\mathrm{O}$ lines. Specifically, differences in mean longevity (averaged across both sexes) between these lines of beetles reared on chickpeas were about 4 days (or 28\%), whereas for the beetles reared on beans it was about 2 days (or 14\%).

Also, as can be seen in Fig. 1A, differences in mean longevity are more pronounced in females than in males; averaged across hosts, $\mathrm{O}$ females outlived $\mathrm{C}$ females by about 5.2 days (or 27\%), whereas in the males these differences amounted to only about 1 day (or 9.6\%), which gives rise to the highly significant Line $\times$ sex term in the three way ANOVA $(P<0.001$; Table 1$)$. A Cox proportional hazard model was used to test differences between the survival curves (Allison, 1995). The mortality curves (Fig. 1B) also differed significantly between the $\mathrm{C}$ and $\mathrm{O}$ females for each host (Cox proportional hazards, $\chi_{(1)}^{2}=$ 126.9 , for bean, $\chi^{2}{ }_{(1)}=153.2$ for chickpea, $P<0.001$ for each). In contrast, the mortality curves of the $\mathrm{C}$ and $\mathrm{O}$ males differed significantly only when beetles were reared on beans $\left(\chi_{(1)}^{2}=30.4, P<0.001\right)$. Because several tests were conducted on these data, probabilities were recalculated using the sequential Bonferroni test to adjust for multiple comparisons.

Beetles reared on beans lived about 1.5 days (or 11\%) longer than beetles reared on chickpea (averaged across each line-sex combination; $\left.\mathrm{F}_{1,1846}=94.6, P<0.001\right)$. However, the average longevities of the $\mathrm{O}$ females reared on bean and chickpea were almost identical (Fig. 1A), which was the main cause of the significant Host $\times$ sex interaction (Table 1). The mortality functions of these females are also identical $\left(\chi_{(1)}^{2}=2.0, P<0.05\right)$, whereas for the $\mathrm{C}$ females the mortality functions differ significantly between hosts (all at the 0.01 level).

\section{Genetic architecture of line differences in longevity}

The additive model was not adequate to explain the hybrid mean longevity for either sex reared on either host (Table 2; Fig. 2). Highly significant $(P<0.001) \Lambda$ tests (Table 2) for each sex-host combination indicate that composite digenic epistatic interactions contributed significantly to the observed differences between the $\mathrm{C}$ and $\mathrm{O}$ lines.

Although estimates of composite additive $[a]$ and dominance [d] effects are unreliable if there is substantial epistasis (Cockerham, 1980), it appears that additive effects of genes are more pronounced on the less suitable host (chickpea) for $A$. obtectus than on bean; for females Wald $\chi_{(1)}^{2}=31.7, P<0.001$, and for males Wald $\chi_{(1)}^{2}=$

TABLE 2. Estimates ( \pm S.E) of composite genetic effects underlying divergence in longevity between $\mathrm{C}$ and $\mathrm{O}$ lines of Acanthoscelides obtectus. Composite genetic parameters are defined in text; a dash indicates that a given parameter was excluded from the most parsimonious model. The weighted residual sum of squares $\left(R S S_{W}\right)$ was tested against $\chi^{2}$ distribution with degrees of freedom (df) equal to the number of crosses minus the number of parameters included in the model. $\Lambda$ (epistasis) tests if adding (or omiting) the three epistatic parameters improves the fit (under the null hypothesis it has a $\chi^{2}$ distribution with $\mathrm{df}=3$ ). $C^{\prime}<0$ implies a negative effect of epistasis on the longevity of $F_{2}$ hybrids.

\begin{tabular}{|c|c|c|c|c|}
\hline \multirow{2}{*}{ Parameters } & \multicolumn{2}{|c|}{ Females } & \multicolumn{2}{|c|}{ Males } \\
\hline & Bean & Chickpea & Bean & Chickpea \\
\hline$m$ & $13.52 \pm 0.69$ & $13.57 \pm 0.16$ & $11.19 \pm 0.12$ & $7.49 \pm 0.40$ \\
\hline [a] & $-1.76 \pm 0.12$ & $-3.41 \pm 0.27$ & - & $-0.87 \pm 0.15$ \\
\hline$[d]$ & $4.18 \pm 1.65$ & - & $-6.89 \pm 0.53$ & $-2.37 \pm 1.02$ \\
\hline$[\mathrm{am}]$ & - & $0.34 \pm 0.14$ & - & - \\
\hline$[d m]$ & - & - & $0.16 \pm 0.11$ & - \\
\hline$[a a]$ & $3.59 \pm 0.68$ & $2.52 \pm 0.29$ & - & $1.91 \pm 0.37$ \\
\hline$[a d]$ & - & $2.99 \pm 0.55$ & $-0.68 \pm 0.25$ & $2.52 \pm 0.38$ \\
\hline$[d d]$ & $-2.18 \pm 1.02$ & $2.53 \pm 0.38$ & $5.07 \pm 0.48$ & $3.64 \pm 0.68$ \\
\hline$R S S_{W}(\mathrm{df})$ & $8.45(4)$ & $0.84(3)$ & $5.96(4)$ & $6.61(3)$ \\
\hline$\Lambda$ (epistasis) & 49.03 & 160.30 & 34.20 & 250.00 \\
\hline$C^{\prime}$ & $-5.01 \pm 1.85$ & $-7.57 \pm 0.98$ & $-5.97 \pm 1.32$ & $-7.46 \pm 1.20$ \\
\hline
\end{tabular}


A

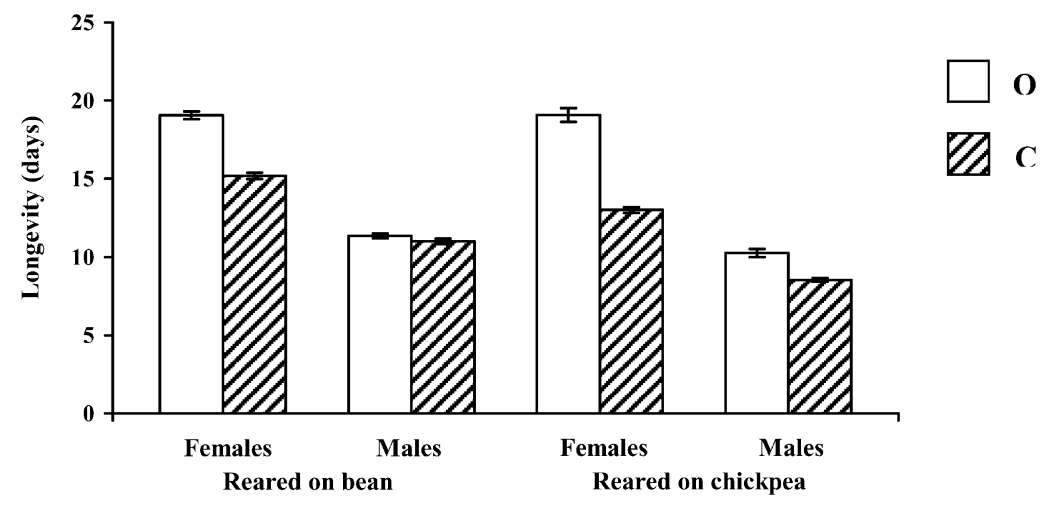

B

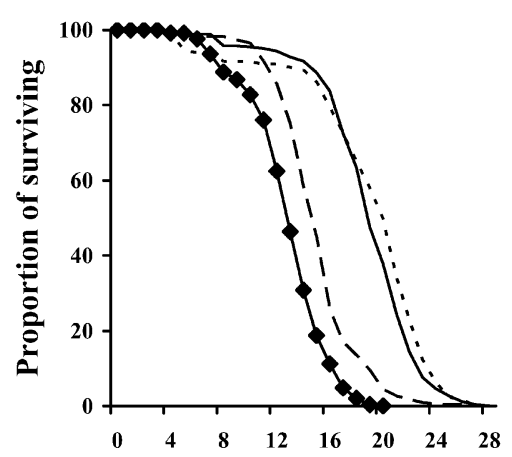

C

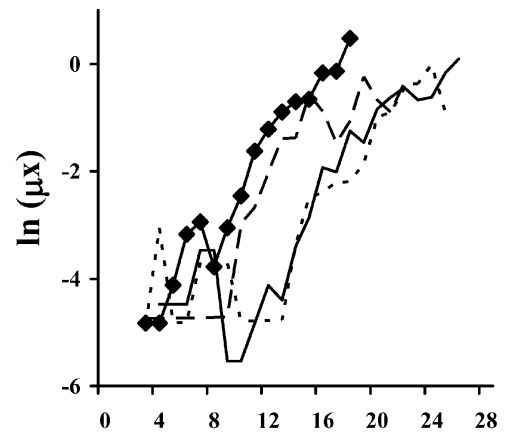

Males
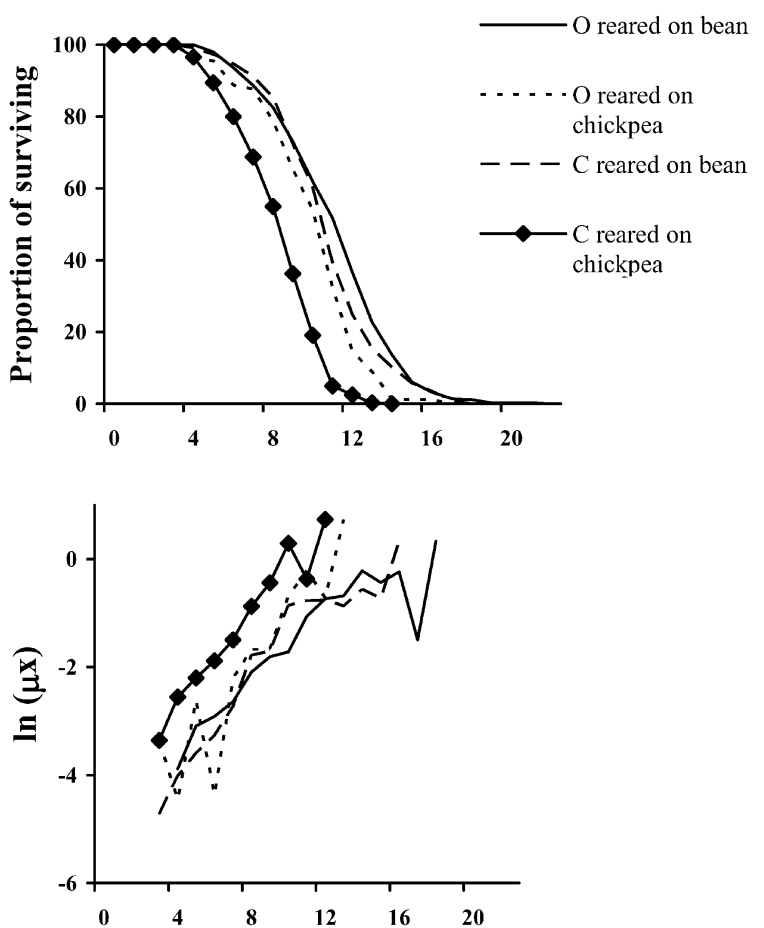

Fig. 1. Mean ( \pm SE) longevity (A), survivorships (B) and ln-transformed mortality curves (C) of Acanthoscelides obtectus females and males of the $\mathrm{O}$ and $\mathrm{C}$ lines reared on bean and chickpea.

23.3, $P<0.001$. In females reared on beans, $[d]$ is significantly positive indicating that alleles that increase longevity are more often dominant than those that decrease it. However, despite insignificant composite dominance effects in chickpea reared females, this parameter was not different from that of females reared on beans (Wald $\chi^{2}{ }_{(1)}$ $=2.5, P>0.05)$. Interestingly, for males reared on both hosts $[d]<0$ and the dominance effect was significantly greater for bean than chickpea reared males (Wald $\chi_{(1)}^{2}=$ 64.9, $P<0.001$ ).

Maternal effects were included in the most parsimonious model for the chickpea females and bean males (Table 2). This significant contribution of additive maternal effects $[\mathrm{am}]$ to longevity implies that mothers carrying a greater proportion of $\mathrm{O}$ line genes tend to produce longer-lived females, irrespective of the offspring's genotype. Marginally $(0.1<P>0.5)$ significant dominant maternal effects $[\mathrm{dm}]$ indicate that bean-reared males of
$\mathrm{F}_{1}$ mothers had, on average, a greater longevity than expected from their genotypes.

The most striking result of the present study are the large digenic epistatic interactions for both sexes and hosts (Table 2). The estimates of dominance $\times$ dominance epistasis $[d d]$ are always significant (though for the beanreared females at the 0.05 level), and with the opposite sign in relation to the dominance effects $[d]$, indicating, according to Mather \& Jinks (1982), that the observed interactions are generally of duplicate type. This type of interaction is associated with traits that have a history of directional selection for extreme expression because it reduces, according to Mather (1967), the number of genotypes of lower fitness in the segregating generations. A highly significant $(\mathrm{P}<0.001)$ additive $\times$ additive epistasis [aa] was observed for all sex-host combinations, except for males raised on beans. These two interaction parameters gave rise to the significant negative values of 
A Reared on bean
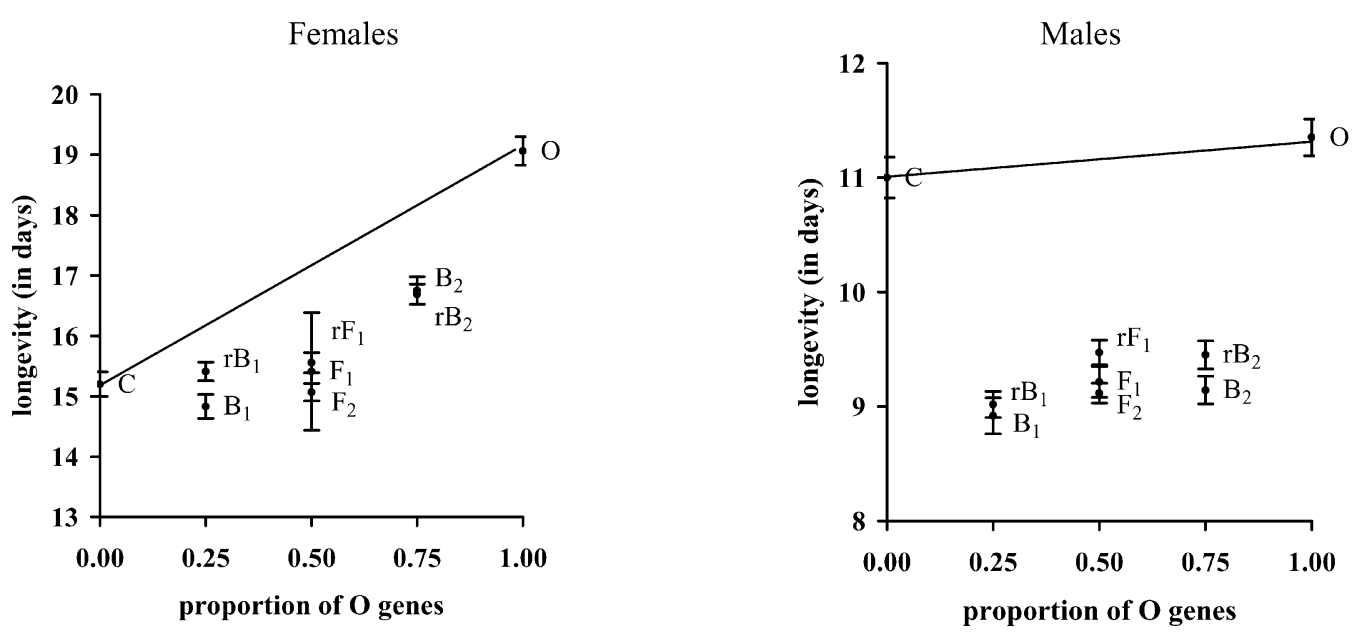

B Reared on chickpea
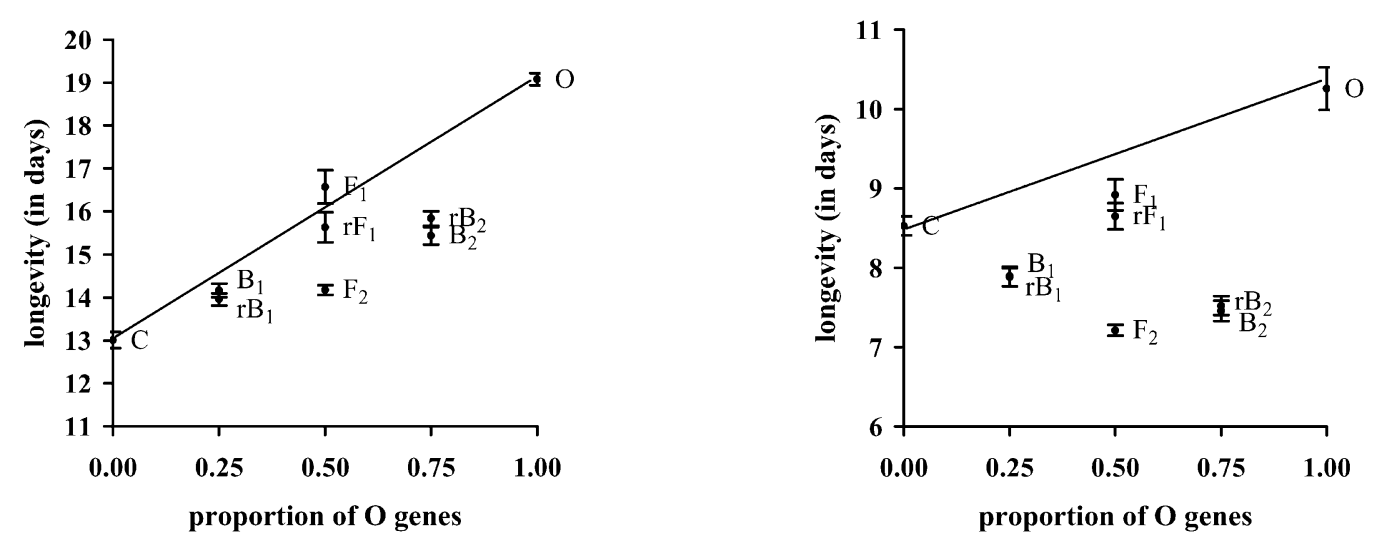

Fig. 2. The mean longevity ( \pm SE) of O, C and hybrid Acanthoscelides obtectus beetles reared on bean (A) and chickpea (B). The line indicate where the hybrid mean should fall if inheritance of the population difference in longevity is purely additive.

the $C$ '-tests (at the bottom in Table 2). Therefore, we were able to conclude that the observed outbreeding depression with respect to longevity (Fig. 2) reflects the presence of significant composite epistatic interactions. In other words, the $\mathrm{C}$ and $\mathrm{O}$ lines have evolved alternative coadapted gene complexes with respect to adult life span. However, it should be noted that epistatic genetic effects were more strongly expressed on chickpeas than beans.

The Wald chi-square test indicated that the most pasimonious models for longevity differ significantly between hosts both for females $\left(\chi^{2}=70.1\right.$, df $=6, P<$ $0.001)$ and males $\left(\chi^{2}=146.9\right.$, df $\left.=6, P<0.001\right)$. The composite genetic effects for longevity also differed between females and males reared on beans (Wald $\chi^{2}=$ $178, .8$, df $=6, P<0.001$ ) or chickpeas (Wald $\chi^{2}=78.0$, df $=6, P<0.001)$.

Although it is theoretically possible to estimate the number of genes, or "genetic factor" contributing to differences in the mean longevity between the $\mathrm{C}$ and $\mathrm{O}$ lines, such analyses are not included here because where there is significant dominance and epistasis such estimates are unreliable (Bradshaw \& Holzapfel, 2000).

\section{DISCUSSION}

As in many other animal species, the longevity and ageing of $A$. obtectus are regulated by both genetic and environmental influences. Here we found significant epistasis, dominance, environmental and sex-specific genetic effects on longevity. This is consistent with results from line-cross and quantitative trait locus studies of D. melanogaster (Wilson et al., 2006 and references therein). However, in contrast Tucić et al. (1997) in an earlier study on the $\mathrm{O}$ lines, report additive inheritance of longevity in this seed beetle. How can this inconsistency be explained? There are three possible explanations, which are not mutually exclusive.

First, this may be partly related to the fact that our previous analyses are of crosses between the $O$ (long-lived) and $\mathrm{Y}$ (short-lived) lines. Because crosses between $\mathrm{C}$ and $\mathrm{O}$ lines were used here, discordance between the previous and present results may be because the effects of specific loci on life span depend on the genetic background in which the genes are expressed (reviewed in the introduction).

Secondly, we studied the longevity of virgin females and males, whereas our earlier study was on mated beetles. Therefore, it seems plausible that, as in D. mela- 
nogaster (Leips \& Mackay, 2002; Vermeulen \& Bijlsma, 2006), genetic mechanisms determining the life span of virgin and mated $A$. obtectus could be partly independent. Moreover, it should be noted that the genetic architecture of $A$. obtectus longevity differed between sexes (Table 2), which also suggests either that different genes affect longevity in females and males, or that the genes have different effects on longevity in females and males. Recent QTL studies have demonstrated that different genes affect female and male longevity in Drosophila (Vieira et al., 2000; Mackay, 2001). Fox et al. (2004) also found differences in the genetic architectures of the females and males of the bruchid beetle (Callosobruchus maculatus).

Finally, the additive inheritance of longevity was recorded in our earlier study after 53 generations of selection for late reproduction, while this study was on $\mathrm{O}$ lines selected for 117 generations. Accordingly, it may be concluded that the relative importance of non-additive variance for longevity increased during the last 64 generations of directional selection for increased longevity. In theory, this could have occurred if directional selection removes additive variance more quickly than it is generated by mutation (Blows \& Hoffmann, 1996).

Alternatively, a potential explanation of the observed increased epistatic interactions is that, as selection for increased longevity progresses, the frequencies of the alleles promoting increased longevity gradually increase (i.e. beneficial allelic combinations are spread in the increased numbers of individual genotypes), which produces a novel type of genetic interaction and releases new genetic variation. This type of interaction between genes may be detected in the line-cross analyses as patterns in epistatic segregation. Eitan \& Soller (2004) named such a response to selection as "selection-induced genetic variation" (SIGV). The empirical support for SIGV was recently provided by Carlborg et al. (2006) who explored the relationship between quantitative genetic (statistical) epistasis and (biological) gene interactions in an intercross between two divergent chicken lines obtained after 42 generations of bidirectinal selection for body weight. Although conventional QTL analysis revealed only a single locus for body weight, they found, by using epistatic QTL mapping, that the genetic architecture of an apparently single gene dissects into a genetic network of four interacting genes. The type of interaction found between the loci in this study "resembles classical Mendelian epistatic segregation patterns, including duplicate epistasis" (Carlborg et al., 2006, p. 420).

If SIGV is the important force shaping the genetic architecture of longevity observed in the present study, as we believed it might, this raises the question of the time scales over which non-additive genetic effects appear in the evolution of fitness-related traits. We have revealed between-line epistasis and dominance for longevity over tens rather than thousands of generations, as predicted by Bradshaw \& Holzapel (2000). Rapid appearance of epistasis, before the loss of substantial additive genetic variation, is recorded for several life history traits of the soapberry bug (Jadera haematoloma; Carroll et al., 2001,
2003). Unfortunately, despite the wide range of empirical observations on animal and plant taxa that suggest the importance of between-population epistasis (e.g. Armbruster et al., 1997; Fenster \& Galloway, 2000; Demuth $\&$ Wade, 2007, and references therein), there is a dearth of evidence on the genetic architecture of populations with known histories of differentiation. Only this information will resolve the time scale of the appearance of epistasis.

In spite of its substantial theoretical importance (see e.g. Lynch \& Walsh, 1998; Demuth \& Wade, 2007), most studies that attempt to measure the genetic architecture of a trait do not account for genotype $\times$ environment in terms of changes in genetic architecture across environments (but see Armbruster et al., 1997; Fenster \& Galloway, 2000). Our study demonstrates that the rearing environment has a profound effect on the genetic architecture of line differences in longevity. Unlike to C. maculatus (Fox et al., 2004), we found that changing the host changed the magnitude of different composite genetic effects for longevity (Table 2), indicating that the effects of genes are not only dependent on the genetic but also the environmental context. Here we detected that nonadditive genetic effects were more strongly expressed when reared on chickpeas than beans. Because chickpeas contain some toxic compounds (see Material and methods), which create more stressful conditions for developing larvae, an increased level of epistasis is not unexpected (Blows \& Sokolowski, 1995). Therefore, the observed outbreeding depression or $\mathrm{F}_{2}$ breakdown with respect to longevity may be a consequence of both the intrinsic effects of interactions between genes from different parental sources (i.e. disruption of coadapted gene complexes) and the genotype $\times$ host interaction (i.e. the loss of local adaptation). Given that realized adult longevity is an important life history trait because it influences how many times an individual can engage in reproduction, our results also have implications for other studies on the genetic architecture of life history traits, which frequently assum that outbreeding depression reflects only the disruption of coadapted gene complexes.

ACKNOWLEDGEMENTS. This study was supported by Ministry of Science and Technological Development of Serbia, project No. 143033. Two anonymous referees provided helpful comments and suggestions.

\section{REFERENCES}

Allison P.D. 1995: Survival Analysis using the SAS System: A Practical Guide, SAS. Institute Inc, Cary, NC.

Armbruster P., Bradshaw W.E. \& Holzapfel C.M. 1997: Evolution of the genetic architecture underlying fitness in the pitcher-plant mosquito, Wyeomyia smithii. Evolution 51: 451-458.

Baldal E.A., Baktawar W., Brakefield P.M. \& ZwaAn B.J. 2006: Methuselah life history in a variety of conditions, implications for the use of mutatants in longevity research. Exp. Gerontol. 41: 1126-1135.

Bieri J. \& KaWECKI T.J. 2003: Genetic architecture of differences between populations of cowpea weevil (Callosobruchus 
maculatus) evolved in the same environment. Evolution 57: 274-287.

Bisby F.A., Buckingham J. \& Harborne J.B. 1994: Phytochemical Dictionary of the Leguminosae. Chapman \& Hall, London, vii + $1051 \mathrm{pp}$.

Blows M.W. \& Hofrmann A.A. 1996: Evidence for an association between nonadditive genetic variation and extreme expression of a trait. Am. Nat. 148: 576-587.

Blows M.W. \& Sokolowski M.B. 1995: The expression of additive and nonadditive genetic variation under stress. Genetics 140: $1149-1159$

Bradshaw W.E. \& Holzapfel C.M. 2000: The evolution of genetic architectures and the divergence of natural populations. In Wolf J.B., Brodie E.D. \& Wade M.J. (eds): Epistasis and the Evolutionary Process. Oxford University Press, New York, pp. 245-263.

Carlborg O., Jacobson L., Ahgren P., Siegel P. \& Anderson L. 2006: Epistasis and the release of genetic variation during long-term selection. Nature Genet. 38: 418-420.

Carroll S.P., Dingle H., Famula T.R. \& Fox C.W. 2001: Genetic architecture of adaptive differentiation in evolving host races of the soapberry bug, Jadera haematoloma. Genetica 112: 257-272.

Carroll S.P., Dingle H.G. \& Famula T.R. 2003: Rapid appearance of epistasis during adaptive divergence following colonization. Proc. R. Soc. Lond. (B) 270: S80-S83.

Charlesworth B. 1994: Evolution in Age-structured Populations. Cambridge University Press, London, xiii +306 pp.

CocKerham C.C. 1980: Random and fixed effects in plant genetics. Theor. Appl. Genet. 56: 119-131.

CURRAN S.P. \& RUvKun G. 2007: Lifespan regulation by evolutionarily conserved genes essential for viability. PloS Genet. 3: e56, doi: 10.1371/journal.pgen.0030056.

Demuth J.P. \& Wade M.J. 2007: Population differentiation in the beetle Tribolium castaneum. I. Genetic architecture. Evolution 61: 494-509.

Eitan Y. \& Soller M. 2004: Selection induced variation - A new model to explain direct and indirect effects of sixty years of commercial selection for juvenile growth rate in broiler chickens, with implications for episodes of rapid evolutionary change. In Wasser S.P. (ed.): Evolutionary Theory and Processes: Modern Horizens Papers in Honour of Eviatar Nevo. Kluwer Academic Publ., Dordrecht, pp. 153-176.

Fenster C.B. \& Galloway L.F. 2000: The contribution of epistasis to the evolution of natural populations: a case study of an annual plants. In Wolf J.B., Brodie E.D. \& Wade M.J. (eds): Epistasis and the Evolutionary Process. Oxford University Press, New York, pp. 232-244.

Fenster C.B., Galloway L.F. \& Chao L. 1997: Epistasis and its consequences for the evolution of natural populations. Trends Ecol. Evol. 12: 282-286.

Finch C.E. \& TANZi R.E. 1997: Genetics of aging. Science 278: $407-411$

Fox C.W., CzesaK M.E. \& Wallin W.G. 2004: Complex genetic architecture of population differences in adult lifespan of a beetle: nonadditive inheritance, gender differences, body size and a large maternal effect. J. Evol. Biol. 17: 1007-1017.

Geiger-Thornsberry G.L. \& Mackay T.F.C. 2004: Quantitative trait loci affecting natural variation in Drosophila longevity. Mech. Ageing Dev. 125: 179-189.

Gilchrist A.S. \& PARTRIDGe L.A. 1999: Comparison of the genetic basis of wing size divergence in three parallel body size clines of Drosophila melanogaster. Genetics 153: $1775-1787$

GLIKSMAN I. \& TuCić N. 1991: Effects of selection for early and late reproduction in low and high larval density populations of the bean weevil (Acanthoscelides obtectus). Genet. Sel. Evol. 23: 119-132.

HAMiLton W.D. 1966: The moulding of senescence by natural selection. J. Theor. Biol. 12: 12-45.

Harshman L.G. 2002: Life span extension of Drosophila melanogaster: genetic and population studies. Pop. Dev. Rev. 29: S99-S126.

LeIPS J. \& MACKaY T.F.C. 2000: Quantitative trait loci for life span in Drosophila melanogaster: Interactions with genetic background and larval density. Genetics 155: 1773-1788.

LeIPS J. \& MaCKAY T.F.C. 2002: The complex genetic architecture of Drosophila life span. Exp. Aging Res. 28: 361-390.

Lynch M. \& Walsh B. 1998: Genetics and Analysis of Quantitative Traits. Sinauer Associates, Sunderland, 980 pp.

MACKAY T.F.C. 2001: The genetic architecture of quantitative traits. Annu. Rev. Genet. 35: 303-339.

MATHER K. 1967: Complementary and duplicate gene interaction in biometrical genetics. Heredity 22: 97-103.

MAther K. \& JinKS J.L. 1982: Biometrical Genetics: The Study of Continuous Variation. Chapman \& Hall, London, 396 pp.

Medawar P.B. 1952: An Unsolved Problem in Biology. H.K. Lewis, London.

Partridge L., Prowse N. \& Pignatelli P. 1999: Another set of responses and correlated responses to selection on age at reproduction in Drosophila melanogaster. Proc. R. Soc. Lond. (B) (Biol. Sci.) 266: 255-261.

Reynolds R.M., Temiyasathit S., Reedy M.M., Ruedi E.A., Drnevich J.M., Leips J. \& Hughes K.A. 2007: Age specificity of inbreeding load in Drosophila melanogaster and implications for the evolution of late-life mortality plateaus. Genetics 177: 587-595.

Rose M.R. 1984: Laboratory evolution of postponed senescence in Drosophila melanogaster. Evolution 38: 1004-1010.

Spencer C.C., Howell C.E., Wright A.R. \& Promislow D.E. 2003: Testing an "aging gene" in long-lived Drosophila strains: Increased longevity depends on sex and genetic background. Aging Cell 2: 123-130.

Stearns S.C., Ackermann M., Doebeli M. \& Kaiser M. 2000: Experimental evolution of aging, growth and reproduction in fruitflies. Proc. Natl. Acad. Sci. USA 97: 3309-3313.

Toivonen J.M., Walker G.A., Martinez-Diaz P., BJedov I., Driege Y., Jacobs H.T., Gems D. \& Partridge L. 2007: No influence of Indy on lifespan in Drosophila after correction for genetic and cytoplasmic background effects. PloS Genet. 3: e95, doi: 10.1371/journal.pgen.0030095.

Tucić N., Stojković O., Gliksman I., Milanović D. \& Š Ešlija D. 1997: Laboratory evolution of life-history traits in the bean weevil (Acanthoscelides obtectus): the effects of densitydependent and age-specific selection. Evolution 51: 1896-1909.

VermeUlen C.J. \& BiJlsma R. 2006: Changes in genetic archtecture during relaxation in Drosophila melanogaster selected on divergent virgin life span. J. Evol. Biol. 19: 216-227.

Vieira C., Pasyukova E.G., Zeng Z.B., Hackett J.B., Lyman R.F. \& MACKAY T.F.C. 2000: Genotype-environment interaction for quantitative trait loci affecting life span in Drosophila melanogaster. Genetics 154: 213-227.

WILLIAMS G.C. 1957: Pleiotropy, natural selection, and the evolution of senescence. Evolution 11: 398-411.

Wilson R.H., Morgan T.J. \& MacKay T.F.C. 2006: Highresolution mapping of quantitative trait loci affect life span in Drosophila melanogaster. Genetics 173: 1455-1463.

ZwaAn B., BiJlsma R. \& Hoekstra R.F. 1995: Direct selection on life-span in Drosophila melanogaster. Evolution 49: 649-659.

Received April 18, 2008; revised and accepted June 28, 2008 